\title{
CRITÉRIOS PARA ANÁLISE DE INOVAÇÕES EM EDIFÍCIOS MULTIFAMILIARES VERTICAIS
}

\section{CRITERIOS PARA ANÁLISIS DE INNOVACIONES EN EDIFICIOS MULTIFAMILIARES VERTICALES}

\section{CRITERIA FOR ANALYSIS OF INNOVATIONS IN VERTICAL MULTIFAMILIAR BUILDINGS}

\section{ACCETE, RAPHAEL}

Bacharel em Arquitetura e Urbanismo, Mestrando em Arquitetura e Urbanismo, UFAL, a7raphael@gmail.com

\section{TOLEDO, ALEXANDRE}

Bacharel em Arquitetura e Urbanismo, Mestre em Arquitetura e Urbanismo, Doutor em Engenharia Civil, UFAL, alexandre.toledo@fau.ufal.br

\section{RESUMO}

A relação entre os arquitetos e o mercado imobiliário é complexa. Os arquitetos buscam atender às solicitações do cliente propondo alternativas criativas. Por outro lado, os agentes do mercado imobiliário buscam segurança e minimização de riscos. Neste cenário, é um desafio projetar edifícios inovadores. No entanto, é possível identificar aspectos inovadores em projetos voltados ao mercado imobiliário por meio de critérios pré-estabelecidos. Dessa forma, o que pode ser considerado inovação no segmento de edifícios multifamiliares verticais? Este artigo tem como objetivo propor critérios para análise de inovações em edifícios multifamiliares verticais construídos, demonstrando o reconhecimento de inovação na produção brasileira de edificações deste segmento. A metodologia baseia-se na observação do que é considerado como inovação em revistas e pesquisas e como isso se atrela a fim de constituir critérios relevantes. Reconhecem-se três tipos de inovação: a) inovação projetual; b) inovação tecnológica; c) inovação ética; e propõe a utilização de seis critérios inseridos nos tipos, sendo eles: flexibilidade de planta, variação tipológica, estrutura e materiais, composição de fachada e volumes, sustentabilidade em projetos de edificações e integração público x privado. As contribuições deste artigo estão na definição de tipos de inovação na arquitetura e, a partir deles, na elaboração de critérios que permitam analisar inovações em projetos arquitetônicos.

PALAVRAS-CHAVE: inovação na arquitetura; critérios de inovação; edifício multifamiliar vertical.

\section{RESUMEN}

La relación entre los arquitectos y el mercado inmobiliario es compleja. Los arquitectos buscan atender las solicitudes del cliente proponiendo alternativas creativas, por otro lado, los agentes del mercado inmobiliario buscan seguridad y minimización de riesgos. En este escenario, es un desafí diseñar edificios innovadores. Sin embargo, es posible identificar aspectos innovadores en proyectos orientados al mercado inmobiliario por medio de criterios preestablecidos. De esta forma, ¿qué puede ser considerado innovación en el segmento de edificios multifamiliares verticales? Este artículo tiene como objetivo proponer criterios para análisis de innovaciones en edificios multifamiliares verticales, demostrando el reconocimiento de una innovación en edificaciones de ese segmento. La metodología se basa en la observación de lo que se considera como innovación en revistas e investigaciones y cómo se atreve a constituir criterios relevantes. Se reconocen tres tipos de innovación: a) innovación proyectual; b) innovación tecnológica; c) innovación ética; y propone la utilización de seis criterios insertados en los tipos, siendo ellos: flexibilidad de planta, variación tipológica, estructura y materiales, composición de fachada y volúmenes, sustentabilidad en proyectos edificaciones e integración pública x privada. Las contribuciones de este artículo están en la definición de tipos de innovación en la arquitectura y, a partir de ellos, en la elaboración de criterios que permitan analizar innovaciones en proyectos arquitectónicos.

PALABRAS CLAVES: innovación en la arquitectura; criterios de innovación; edificio multifamiliar vertical.

\section{ABSTRACT}

The relationship between architects and the real estate market is complex. Architects seek to respond to customer requests by proposing creative alternatives; on the other hand, real estate agents seek safety and risk minimization. In this scenario, it is a challenge to design innovative buildings. However, it is possible to identify innovative aspects in projects focused on the real estate market through pre-established criteria. In this way, what can be considered innovation in the segment of vertical multifamily buildings? This article aims to propose criteria for analysis of innovations in vertical multifamily buildings, demonstrating the recognition of an innovation in buildings of this segment. The methodology is based on the observation of what is considered as innovation in journals and researches and how this is linked to constitute relevant criteria. Three types of innovation are recognized: a) design innovation; b) technological innovation; c) ethical innovation; and proposes the use of six criteria inserted in the types, being: plant flexibility, typological variation, structure and materials, composition of facade and volumes, sustainability in projects of buildings and public $x$ private integration. The contributions of this article are in the definition of types of innovation in the architecture and, from them in the elaboration of criteria that allow to analyze innovations in architectonic projects.

KEYWORDS: innovation in architecture; innovation criteria; vertical multifamily building. 


\section{INTRODUÇÃO}

A relação do arquiteto com os agentes imobiliários é complexa. O projeto, atualmente, envolve muitos agentes e diversas disciplinas diferentes que se relacionam entre si. A elaboração de um projeto de arquitetura tem por base a otimização dos problemas complexos e a análise de possíveis respostas a eles. Para Lawson (2011) esse é um processo fundamentalmente baseado em priorizar algum aspecto em detrimento de outro, quando esses forem conflitantes entre si.

Em um projeto arquitetônico estão envolvidos, entre outros agentes, os arquitetos, os clientes e os construtores. Os arquitetos, que buscam soluções técnicas e artísticas, produto da criatividade empregada por eles para atender às demandas do cliente que, no segmento de projetos para o mercado imobiliário é, frequentemente um construtor ou um incorporador (KOWALTOWSKY et al, 2011).

Segnini (2014) afirma que esses agentes, por sua vez, tentam se adaptar às demandas do consumidor final e por investirem grandes quantias para construir o imóvel e agregar valores de troca a eles para obter retorno financeiro. Pela forma como enxergam o projeto - como um produto de seu negócio - buscam minimizar riscos e cercarem-se de segurança para seus empreendimentos e isso resulta em uma padronização dos projetos.

Isso gera, de certa forma, um desafio ao arquiteto que se dispõe a tentar inovar nos projetos; sendo o desafio ainda maior, pois necessita dispor de uma relação com a construção cada vez mais abrangente no que diz respeito à quantidade de disciplinas relacionadas ao projeto nas quais precisa atuar.

Azevedo (2014) afirma que é possível notar que há um processo de padronização projetual quando se considera a produção multifamiliar no Brasil, sendo necessário apenas uma rápida olhada em propagandas de empreendimentos imobiliários para se comprovar essa afirmação. De maneira semelhante, a observação dos edifícios durante uma caminhada pelas ruas da cidade ratifica a repetitividade dos projetos. Portanto, "o percurso por entre a multiplicidade de torres similares nos remete a uma experiência déjà vu" (AZEVEDO, 2014, p.22).

Nesse cenário, Villa e Ornstein (2010) observaram que empresas da construção civil têm procurado aumentar seus índices de produtividade, a fim de aumentarem sua competitividade. Costa (2002, apud Vargas, 2014, p. 59) identifica que a ambição do mercado imobiliário mudou com o passar dos anos:

- 1970: atender às necessidades dos clientes;

- 1980: antecipar as necessidades do consumidor;

- 1990: despertar no consumidor encantamento e desejo;

- 2000: proporcionar ao cliente interação e experiências.

Vargas (2014) completa afirmando que, atualmente, o mercado imobiliário atua buscando proporcionar a personalização dos imóveis, apresentando-os como exclusivos, únicos, diferenciados dos demais.

Porém, o que se observa é que essa diferenciação só ocorre nos projetos voltados para estratos mais ricos da sociedade, de forma que empreendimentos "Padrão A" recebem inovações, seja em marketing, em produto - projetuais ou tecnológicas - ou ainda em aspectos éticos. Já em edifícios "Padrão B", ou seja, aqueles não são voltados para o público de alta renda, predomina a padronização recorrentemente citada pelos autores.

A literatura brasileira, especificamente sobre conceitos de inovação na arquitetura, ainda é escassa, principalmente na produção acadêmica do século XXI, haja vista que as definições encontradas foram, em sua maior parte, do século passado. Além disso, o termo é usado de maneira vaga e sem critérios em premiações de projetos e revistas da área.

Uma das tentativas de conceituar inovação vem de Barros (1996), que afirma que inovação em arquitetura pode ser encontrada em processos construtivos, na mecanização da produção, na formação de novos produtos para construção civil e em tecnologias de informação.

Fuck e Vilha (2012, p. 3) afirmam que "a palavra inovação relaciona-se ao ato de inovar, ao ato de fazer algo novo". Em uma sociedade na qual mudanças são bastante frequentes, a inovação torna-se objeto de análise em diversas disciplinas, muitas vezes sem se ter um cuidado conceitual ao abordá-la. Os autores ainda trazem informações sobre o tema: 
$\mathrm{Na}$ internet, por exemplo, o termo é bastante utilizado. Uma pesquisa rápida utilizando o famoso "Google" indica mais de 20 milhões de resultados para a palavra "inovação". Se a pesquisa for feita com a palavra "innovation", o número é ainda mais surpreendente: mais de 315 milhões de resultados. É claro que os números em si não captam o real significado do que está acontecendo na atualidade, mas eles nos dão uma pista interessante sobre a importância que vem sendo atribuída ao tema (FUCK E VILHA, 2012, p. 3).

Apesar da escassez de literatura conceituando diretamente inovação na arquitetura e como deve ser analisada, é possível encontrar na produção arquitetônica o que Azevedo (2014) classifica como "iniciativas de exceção", que seriam fatores de promoção de uma arquitetura menos padronizada em diversos aspectos.

Dessa forma, embora possa haver mais variantes, é possível perceber que na arquitetura existem pelo menos três categorias de inovação encontradas mais comumente: a projetual, a tecnológica e a ética.

O primeiro tipo - a inovação projetual - geralmente deriva de problemas encontrados no processo de projeto e não pode ser considerado uma obra do acaso ou puramente inspiração. Desse modo, Mahfuz (1984) afirma que o caminho mais apropriado é, em vez de encarar a produção arquitetônica como produto de uma inspiração divina ou um papel em branco, entender como um processo de transformação do conhecimento. Assim, a produção arquitetônica inovadora tem mais relação com a criação de partes e detalhes do projeto, e o arquiteto no processo de projeto utiliza métodos de projeto como mimético, inovativo, normativo e tipológico.

O segundo tipo - a inovação tecnológica - respalda-se na abordagem de Vilha (2009), ao considerar que a inovação tecnológica atualmente é considerada essencial nas estratégias voltadas à diferenciação, competitividade e crescimento de negócios. Dessa forma, as estratégias inovadoras adotadas nas empresas estão associadas à uma busca por se diferenciar de uma forma suficiente para produzir produtos e serviços para o mercado, de maneira que isso gere vantagem competitiva em relação aos concorrentes.

O terceiro tipo - a inovação ética - surge a partir de contribuições diferentes de diversas disciplinas, não apenas ligadas à arquitetura. Isso resulta em novas possibilidades de se abordar determinado assunto e isso favorece o surgimento da inovação; além da interdisciplinaridade ser capaz de permitir o conhecimento do que Batista (2016, p. 3) afirma ser "outra dimensão da ciência: a ética".

Porém, como é possível, nesse cenário, identificar inovações em edifícios residenciais multifamiliares verticais com critérios bem definidos? O artigo deriva de pesquisa de mestrado do mesmo autor na qual analisa-se o emprego de inovações nos empreendimentos vencedores do Prêmio Master ADEMI-AL ${ }^{1}$ e tem por objetivo propor critérios para análise de inovações em edifícios verticais multifamiliares construídos, demonstrando como se dá o reconhecimento de uma inovação na produção brasileira de edificações deste segmento.

\section{METODOLOGIA}

Este artigo se ateve a propor, com base nos tipos de inovação sugeridos por Mahfuz (1984), Vilha (2009) e Batista (2016), critérios de análise de inovações na produção de edifícios multifamiliares verticais, produto principal do mercado imobiliário.

Para definir o tipo de empreendimento que se encaixa nessa análise foi utilizada a afirmação de Chacon (2004), que caracteriza edifício multifamiliar como uma conjunção de unidades residenciais privativas que possuem cômodos habitáveis como sala e quarto; um setor específico para cocção dos alimentos (cozinha) e um compartimento destinado à higiene pessoal e alívio de necessidades fisiológicas (banheiro), sendo esses cômodos conectados por uma circulação comum e cujos pavimentos se interligam por meio de circulação vertical (escadas e/ou elevadores).

Primeiramente, procedeu-se pesquisa em meio eletrônico com o termo "inovação na arquitetura" e os resultados da busca listaram as vezes em que o termo foi citado em matérias de sites e artigos de revistas. Posteriormente, realizou-se uma filtragem dos resultados da seguinte forma: à medida que o termo aparecia se repetindo quando a abordagem tratava de projetos de arquitetura - por exemplo, quando o termo "flexibilização de planta" se repetiu em diversas matérias de revistas especializadas na área - criou-se ali a possibilidade que esse item, ao ser abordado com frequência, passasse a ser considerado um critério de análise.

Dessa forma, foi observada a constância de repetição de seis itens, sendo eles: (i) flexibilização de planta; (ii) variação tipológica; (iii) estrutura e materiais; (iv) composição de fachada e volumes; (v) sustentabilidade 
em projetos de edificações; e (vi) integração público x privado. Para que fossem definidos como critérios, se fez necessário que os termos encontrassem resposta na literatura acadêmica. Isso possibilitou que se encontrasse, na frequência em que os itens surgiam, um referencial do que pode ser considerado inovação em arquitetura, resultando no que a pesquisa definiu como "critérios de análise".

Após esse processo, realizou-se uma busca por dissertações, teses, artigos, trabalhos apresentados em congresso e documentos específicos sobre essas temáticas, a fim de se obter respaldo teórico para a definição dos critérios.

Baseando-se na literatura existente sobre o tema e fazendo um trabalho de análise prévia dos critérios encontrados, diagnosticou-se que eles seriam melhor observados se alocados em três tipos de inovação, sendo elas: a) projetuais; b) tecnológicas; c) éticas. Dentro desses tipos, os seis critérios de análise foram organizados da seguinte forma:

Quadro 1 - Tipos de inovação e respectivos critérios de análise.

\begin{tabular}{|c|c|}
\hline TIPO DE INOVAÇÖES & CRITÉRIOS DE ANÁLISE \\
\hline PROJETUAIS & $\begin{array}{c}\text { FLEXIBILIZAÇÃO DE PLANTA; } \\
\text { VARIAÇÂO TIPOLÓGICA. }\end{array}$ \\
\hline TECNOLÓGICAS & ESTRUTURA E MATERIAIS; \\
COMPOSIÇÃO DE FACHADA E VOLUMES
\end{tabular}

Por fim, realizou-se uma busca por exemplos de edifícios residenciais multifamiliares em fase de lançamento, construção ou já habitados no Brasil que preenchessem os requisitos, a fim de se enquadrar em algum dos critérios de análise definidos.

\section{INOVAÇÕES PROJETUAIS}

\subsection{Flexibilidade de planta}

Xavier (2016) destaca que o conceito de flexibilidade pode ser compreendido como a possibilidade que os usuários têm de modificar o ambiente, adaptando-o às suas necessidades e expectativas. Entretanto, a flexibilidade não finda na escolha de um layout diferente, incluindo também a possibilidade de englobar novas tecnologias em virtude de mudanças na sociedade, a fim de transformar o espaço residencial para qualquer outro fim.

Vargas e Araújo (2014) afirmam que o mercado imobiliário se apoderou dos princípios do modernismo somente naquilo que interessava a ele, por exemplo, ao fazer propaganda de uma suposta planta flexível enquanto o modo de compartimentação dos cômodos ainda fosse o tradicional; ou incorporando o uso misto nos empreendimentos; ou assumindo unidades mínimas, mas ofertando equipamentos de uso comum de lazer e serviços; ou ainda apenas excluindo adornos das fachadas - uma maneira de reduzir custos, inclusive.

A opção de "flexibilidade" surge a partir de um desejo maior do cliente em personalizar seu imóvel. Entretanto, isso não se configura plenamente na prática, pois o resultado acaba sendo apenas apartamentos muito parecidos ou até mesmo padronizados com uma roupagem diferente para serem mais vendáveis. Tramontano (2004) entende que essa possibilidade de flexibilizar a planta, que o mercado imobiliário vende como uma "inovação", é só uma tentativa de minimizar a sensação de pouco espaço ao reduzir áreas dos ambientes.

Seres humanos possuem uma característica que é a necessidade de adaptação do local no qual estão inseridos, a fim de adequá-lo às suas necessidades (XAVIER, 2016). O mercado imobiliário já percebeu isso e aposta na oferta de edifícios nos quais o cliente possa intervir. 
Algumas construtoras e incorporadores já produzem edifícios que apresentam diferenciais significativos aos demais. Um caso inovador em flexibilização de plantas é o edifício MaxHaus Campo Belo², projetado pelo escritório RoccoVidal Perkins+Will. O edifício revela um conceito de arquitetura flexível, deixando a planta livre (Figuras 1 e 2) para o usuário utilizar conforme suas necessidades e até então é um representante significativo deste conceito.

Figura 1: Planta tipo do edifício MaxHaus Campo Belo.

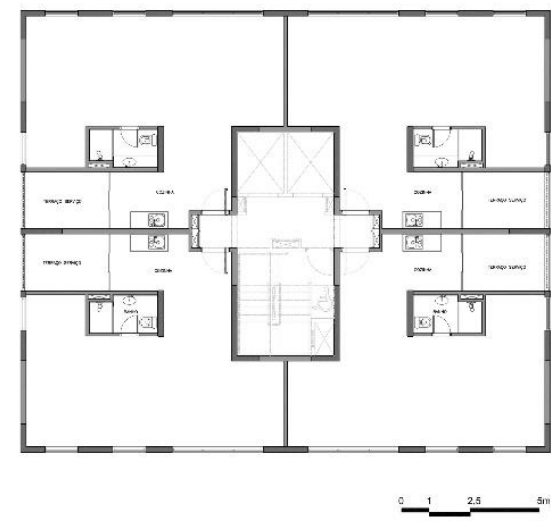

Fonte: Daniel Ducci ${ }^{3}$
Figura 2: Imagem interna do apartamento do edifício MaxHaus Campo Belo.

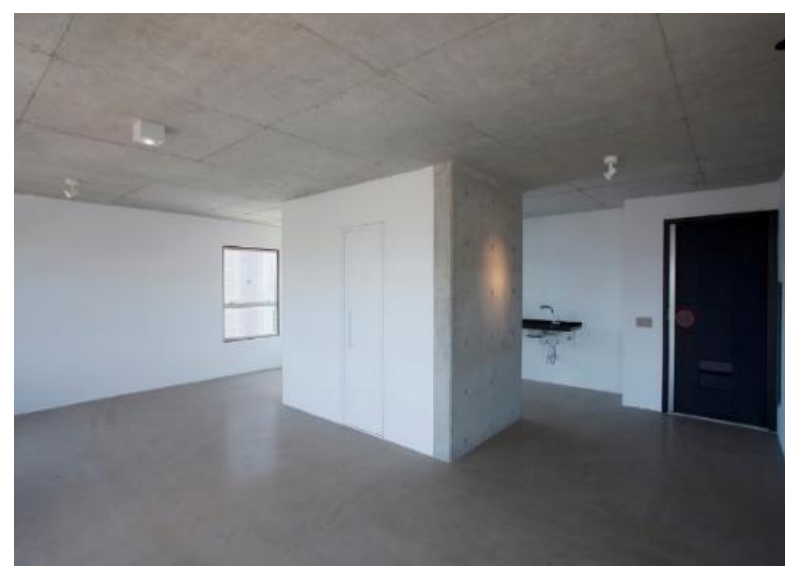

Fonte: Daniel Ducci ${ }^{4}$

Outro exemplo de flexibilização de planta é o edifício VN Quatá5, do escritório Basiches Arquitetos Associados, que aposta no apartamento mínimo considerando que o seu público prefere fazer serviços diários da casa como lavar roupa fora do apartamento. O condomínio possui um espaço para co-working, mas o principal aspecto a ser considerado nesse empreendimento é a aposta na flexibilidade (Figuras 3 e 4), inspirada nos empreendimentos Life Edited ${ }^{6}$, no qual o cliente tem permissão para modificar a planta de acordo com suas necessidades.

Xavier (2016) ainda afirma que fica em evidência a aproximação do projeto com o usuário quando o edifício é projetado em condições reais de ser adaptado às necessidades dos moradores, de forma que o usuário não seja um agente passivo dentro do apartamento.

Figura 3: Perspectiva comercial interna de um apartamento com possibilidade de anexar o pavimento acima duplicando o pé-direito.

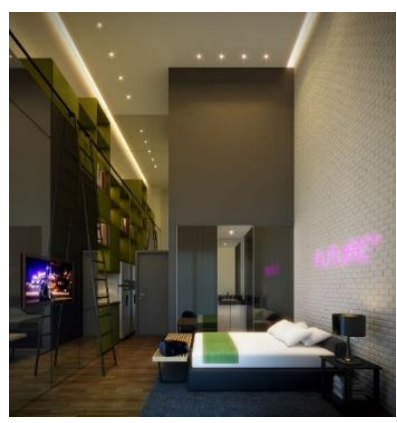

Fonte: Vitacon ${ }^{7}$
Figura 4: Perspectiva comercial interna de um apartamento com possibilidade de torná-lo duplex anexando o pavimento imediatamente acima.

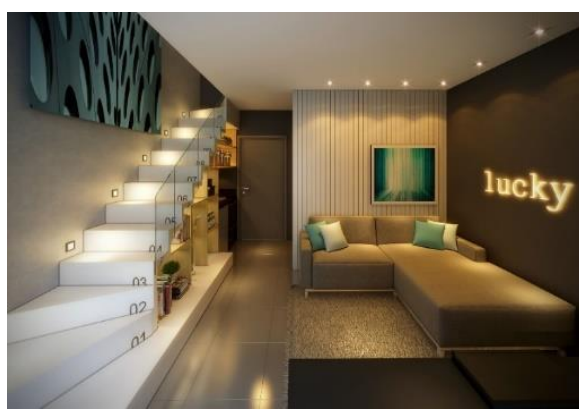

Fonte: Vitacon ${ }^{8}$

\subsection{Variação tipológica}

Tipologia, por sua vez, olhando sob a construção de Aymonimo (1973 apud MONTANER, 2001), é entendido como um mecanismo e não um grupo, sendo, portanto, uma metodologia de análise envolvendo uma relação entre as partes da unidade construtiva e o todo analisado. 
Montaner (2001, p. 110) complementa dizendo que:

A palavra 'tipo' não representa tanto a imagem de uma coisa a copiar ou a imitar perfeitamente, mas sim a ideia de um elemento que, por si mesmo, deve servir de regra. [...] O 'modelo', entendido de acordo com a evolução prática da arte, é um objeto que deve repetir-se tal como é; o tipo é, pelo contrário, um objeto em função do qual se pode conceber obras que não se assemelham nada entre si. No modelo tudo é dado e preciso; no tipo tudo é mais ou menos vago. Assim, a imitação dos tipos não tem nada que o sentimento ou o espírito não podem reconhecer [...].

Chacon (2004, p. 121) ainda acrescenta que, o fato de se estudar tipologicamente o projeto arquitetônico, revela a "evolução da formação da paisagem construída", contribuindo para "caracterizar seu papel estético".

A mesma ideia é expressa por Colquhoun (1974), quando afirma que a tipologia na arquitetura revela a normativa e os valores estéticos armazenados e resultantes de fatores culturais, que regem a constante transformação pela qual sofre. De forma semelhante, Gavazza e Toledo (2016) avaliam que a variação tipológica9 ${ }^{9}$ acontece em virtude das constantes mudanças nos hábitos de morar, do perfil familiar diversificado e do padrão econômico dos usuários.

Um exemplo de variação tipológica - e nesse exemplo ela afeta diretamente os aspectos estéticos citados por Chacon (2004) e Colquhoun (1974) - é o edifício Fidalga 727 / São Paulo ${ }^{10}$, projeto do escritório Triptyque Architecture. Ele é caracterizado por unidades habitacionais sobrepostas verticalmente seguindo uma variação sem linearidade e sem modulação, tanto em se tratando de aberturas na fachada (Figura 5) como de tipologia (Figura 6).

Figura 5: Perspectiva computadorizada do edifício Fidalga 727 / São Paulo demosntrando a variação de aberturas provenientes da variedade tipológica encontrada no projeto.

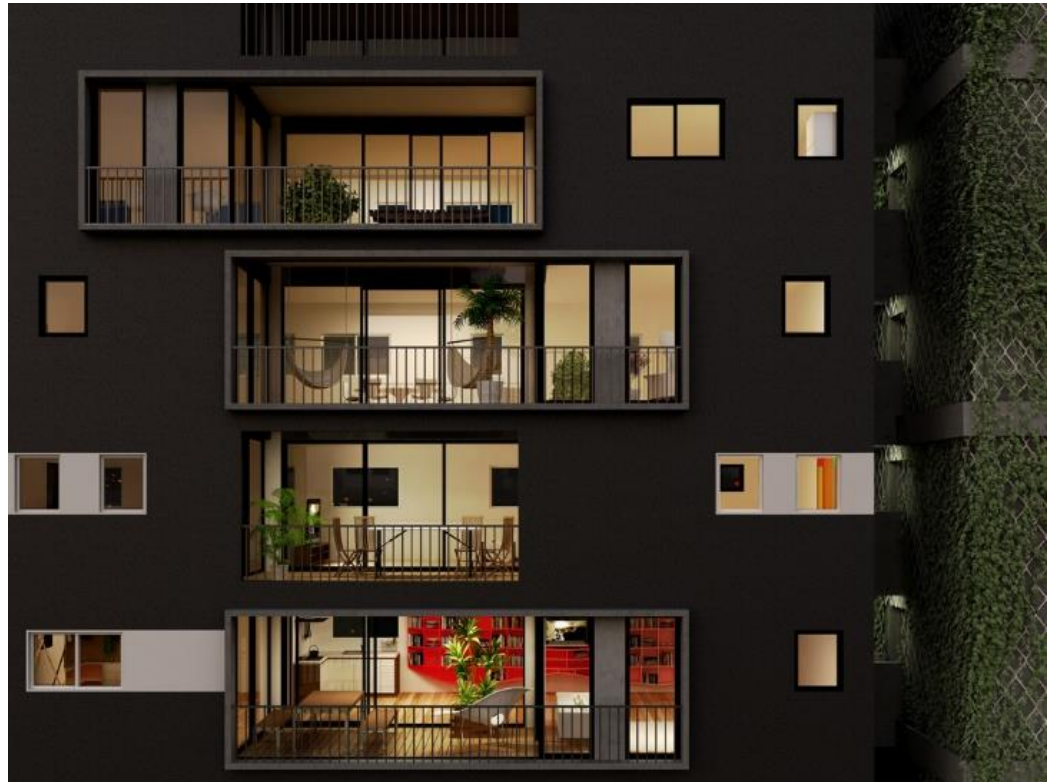

Fonte: Fran Parente ${ }^{11}$
Figura 6: esquemática de plantas demonstrando a variação de tipologias no edifício. Fidalga 727.

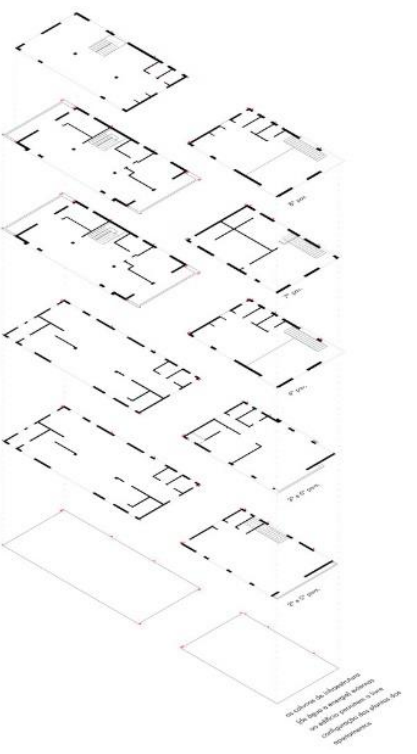

Fonte: Fran Parente ${ }^{12}$

O processo de análise tipológica, até chegar na formação de uma tipologia, não é algo engessado que se resume à estatística ou classificações pura e simplesmente. A ideia é apresentar um guia tipológico ao arquiteto durante todo o processo de criação (ARGAN, 2001). Portanto, para identificar um tipo é necessário que se isole, em cada projeto, alguns aspectos peculiares a eles, posteriormente, mantendo apenas os elementos comuns a todos. O tipo acaba sendo definido por analogia, reduzindo a uma forma básica comum aos projetos analisados. 


\section{INOVAÇÕES TECNOLÓGICAS}

\subsection{Estrutura e Materiais}

Niemeyer (2003) entendia que os materiais e as técnicas construtivas possibilitavam a inovação na forma plástica da arquitetura, até porque estão em constante mudança, em virtude da evolução dos mesmos.

De forma semelhante, Pisani (2012, p. 11) afirma que:

Os aspectos técnicos e construtivos podem qualificar tanto a forma da proposição arquitetônica quanto os elementos da construção, pois estes trabalham de forma interdependente e ambos carecem atender à intenção plástica desejada.

Reduzir o papel do sistema estrutural a uma função apenas de sustentar os edifícios é um equívoco e, segundo Grala da Cunha (2011), é isso que tem acontecido. No entanto, o mesmo autor explica que existem exceções que inovam, pois não se moldam ao padrão da maioria das construções. Dessa forma, nesses projetos, a estrutura do edifício recebe uma posição de destaque na composição arquitetônica ${ }^{13}$.

Os sistemas estruturais se propõem a representar um papel funcional e formal no projeto arquitetônico sendo o papel funcional fortemente ligado à necessidade de se sustentar e possibilitar ao edifício ser executado na forma projetada pelo arquiteto e o papel formal o responsável por colocar a estrutura em situação destacada no projeto. E nesse sentido da forma que a estrutura valoriza a dimensão tecnológica do projeto, abarcando as inovações que surgem e agregam (GRALA DA CUNHA, 2011).

Inovações em estrutura e materiais encontram expressão significativa no modernismo, quando os arquitetos utilizavam suas obras como discursos sobre a técnica de exploração dos materiais. Oscar Niemeyer procurava empregar em obras públicas aquilo que era desenvolvido em termos de engenharia nacional; Villanova Artigas utilizava-se de estruturas de concreto armado e lajes nervuradas para permitir a sustentação de vãos; Paulo Mendes da Rocha discursava sobre a exibição do conhecimento técnico apreendido pelo arquiteto; João Filgueiras Lima explorava a lógica de montagem; e de diversas formas, muitos outros arquitetos expressavam suas obras por meio da lógica estrutural (MACIEL, 2006).

Lina Bo Bardi (2003, p. 271-3) expressa bem essa incorporação da estrutura ao projeto arquitetônico como algo fundamental:

(...) A estrutura de uma obra de arquitetura tem que ser projetada por um arquiteto, mesmo se calculada por outros, mas os problemas, que eu chamei de prática científica, devem ser conhecidos (...)

Bacellar, Souza e Machado (2004, p. 3.609), ao explicarem que as empresas do ramo de construção civil precisam estar constantemente inovando, em virtude das mudanças que a sociedade sofre com o tempo, afirmam que a inovação, além de representar o significado superficial que é "novidade, avanço científico, descoberta ou invenção aplicadas ao produto", necessita que haja aceitação pelo mercado, de forma que traga retorno financeiro. Dessa forma, "a adoção de novas tecnologias, novos materiais e novos processos são imperativos para a sobrevivência das empresas".

O processo de inovação tecnológica se relaciona com a criatividade, pois é um processo que começa a partir de uma ideia técnica concretizada quando surge um novo produto (JACOSKI, 2003). Nesse aspecto, a contribuição de Kowaltowski et al (2011, p. 6) se alinha com a de Jacoski (2003) ao afirmar que "a criatividade gera novidade, ideias e soluções úteis para resolver problemas e desafios rotineiros, resultando em invenções ou produtos de valor científico, técnico, social e estético".

Em geral, mudanças na sociedade e na tecnologia interferirem no modo de morar e, consequentemente, na produção arquitetônica (DUARTE, 2016). Por isso, buscando inovar, incorporadoras como a MaxHaus tem como principal característica o slogan "more na sua época", focando em apresentar ao cliente uma experiência tecnológica e "futurística" (Figura 7) apostando na tecnologia para realizar atividades diárias como abrir a porta, definir som da campainha, controle de luminosidade, dentre outros processos de automação e, na flexibilidade, permitindo ao cliente modificar a configuração espacial do seu apartamento por meio de aplicativos. De forma semelhante, a Ritz Incorporações vende o seu produto Ritz Residence com a frase "perto dele o futuro é passado" (Figura 8), visando demonstrar a modernidade tecnológica do empreendimento e assim atingir o público-alvo, nesse tipo de proposta, normalmente visando o mercado de luxo. 
Figura 2 - Campanha publicitária da construtora MaxHaus valorizando aspectos tecnológicos do projeto.

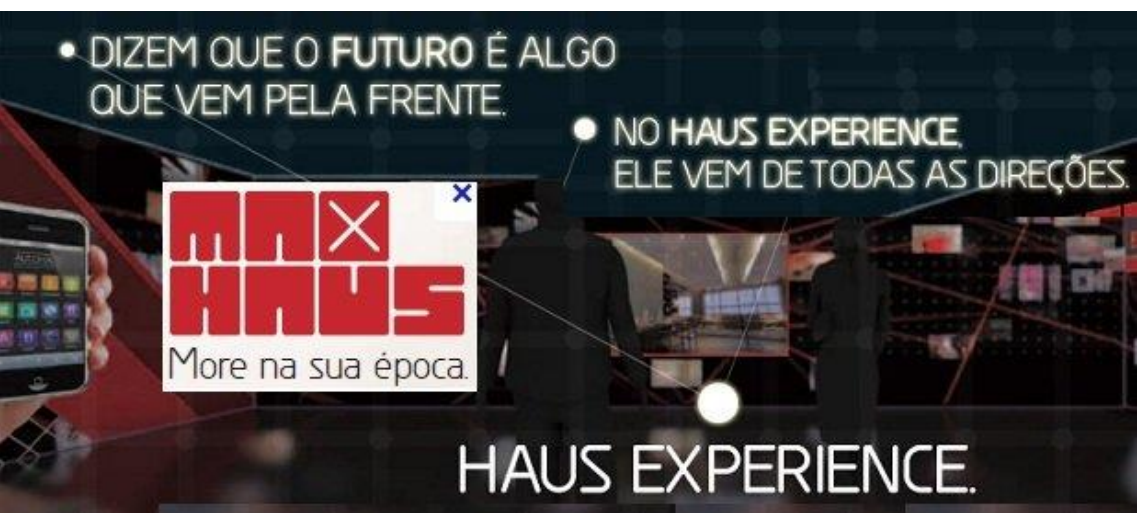

Fonte: DHI Imóveis ${ }^{14}$
Figura 3 - Folder puclitiário do edifício Ritz Residence.

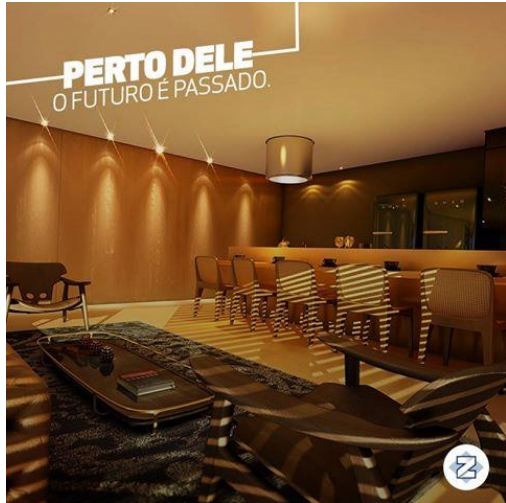

Fonte Zampieri Imóveis ${ }^{15}$

\subsection{Composição de fachada e volumes}

Em um dos seus livros, Ching (1998) se dedica a apresentar elementos e sistemas que possibilitem analisar um projeto arquitetônico: a arquitetura do espaço; estrutura e delimitação; o movimento no tempo/espaço; tecnologia; programa; e o contexto no qual está inserido.

Eisenman (2011) contribui adicionando que era necessário fazer o que ele chamou de "leitura dos detalhes". Primeiramente, se faz a descrição do projeto e a análise utilizando-se também da interpretação do observador. Posteriormente, faz uso de diagramas para entender melhor os projetos e suas intenções.

Cavalcante (2014, p. 94) estabeleceu que:

as definições espaciais e formais permitem a análise do partido adotado e suas soluções funcionais, a setorização e a compartimentação, os acessos, o conforto, o volume e a sua distribuição, a fachada e seu estudo compositivo (elementos da composição visual).

Cavalcante (2014) ainda elenca alguns critérios disciplinares de análise como:

- tipologia do lote, que identifica a geometria e localização na quadra, descrevendo o lote como "de esquina" ou "face de lote";

- implantação no lote, identificando a inserção do edifício no lote, a quantidade de edificações, observando recuos, afastamentos e taxas de ocupação baseadas na legislação vigente;

- especificações espaciais e formais: analisam o partido adotado, soluções funcionais, setorização, acessos, distribuição de volumes e a composição da fachada

Ching (1998) afirma que em arquitetura, o volume pode ser considerado como uma parte de um espaço delineado por paredes, pisos ou cobertas, ou a quantidade de espaço que a massa de um edifício ocupa. Já quando o foco da análise é a fachada, é considerada a relação entre cheios e vazios, a verticalidade ou horizontalidade do edifício, proporção face ao todo da edificação, uso da cor, sombras e texturas (CAVALCANTE, 2014).

O edifício Ritz Residence ${ }^{16}$, situado em Maceió-AL, possui uma característica peculiar que é a forma como os volumes de pele de vidro sacam de um plano inicial que carrega a estrutura do prédio (Figura 9), além disso, propõe aberturas em formas elípticas e desencontradas na lateral do volume. O edifício Fidalga 727 / São Paulo ${ }^{17}$ se destaca na paisagem diferenciando-se do entorno, no qual se encontram construções verticais em moldes modernistas e ocupações até três andares. Nesse prédio, a fachada recebeu materiais como asfalto negro e pintura simples nas janelas, além de ter tido sua forma determinada pela variação das tipologias dos pavimentos e alocação aleatória das aberturas (Figura 10). 
Figura 4 - Perspectiva comercial do edifício Ritz Residence.

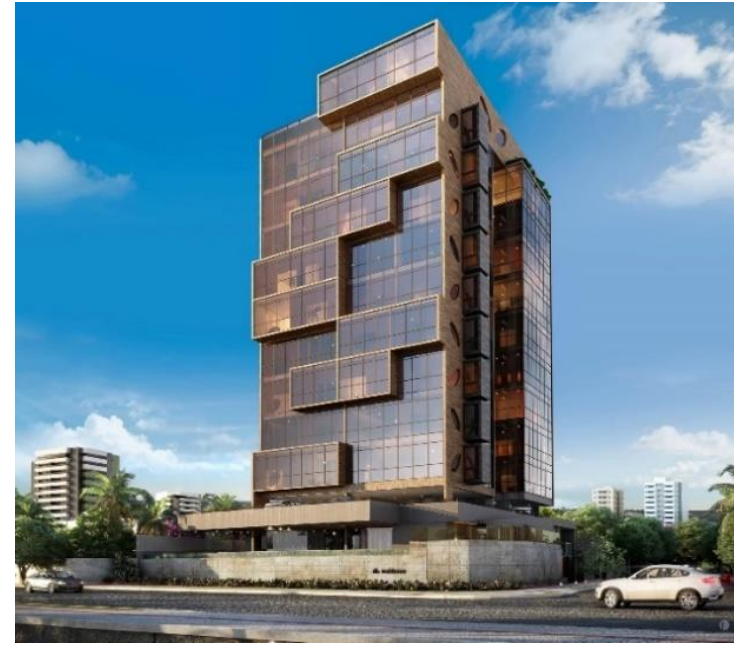

Fonte: Ritz Incorporações ${ }^{18}$
Figura 5 - Foto aérea do edifício Fidalga 727 / São Paulo.

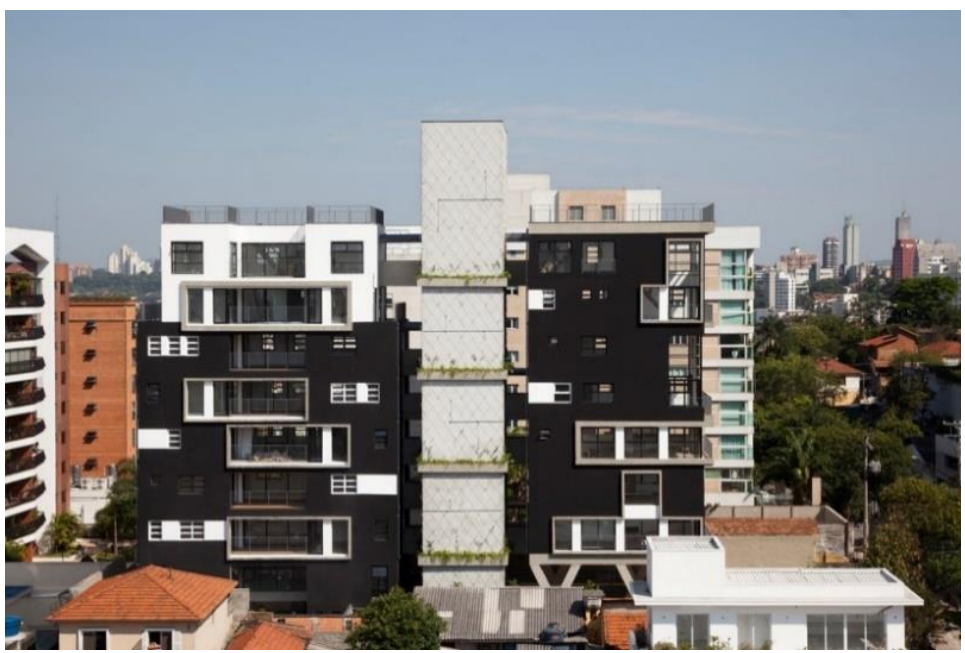

Fonte: Fran Parente ${ }^{19}$

\title{
5 INOVAÇÕES ÉTICAS
}

\subsection{Sustentabilidade em projetos de edificações}

O emprego de práticas sustentáveis na construção civil é uma tendência. Dessa forma, as construtoras, com o objetivo de obter certificados e, consequentemente, status de empresas sustentáveis, tendem a planejar suas obras a partir de premissas focadas na sustentabilidade (OLIVEIRA, 2015).

O tema "sustentabilidade", quando pensado de maneira mais abrangente, atinge aspectos socioeconômicos e ambientais. Gonçalves e Duarte (2006) afirmam que foi o Brundtland Report (1987) que definiu primeiramente o desenvolvimento sustentável, afirmando que é aquilo que atende às necessidades do presente, sem comprometer as demandas do futuro.

$\mathrm{Na}$ arquitetura, o conceito de sustentabilidade chegou no início da década de 1990. No tocando ao edifício, a partir da Segunda Guerra Mundial, se viu uma repetição de caixas de vidro e um aumento grande do consumo de energia nas décadas que vieram (GONÇALVES; DUARTE, 2006). Isso fez o mundo voltar os olhos para o desenvolvimento sustentável, não apenas na arquitetura, mas também no urbanismo.

Nesse sentido, Corbella e Yannas (2003, p. 17) afirmaram que:

\begin{abstract}
A Arquitetura sustentável é a continuidade mais natural da Bioclimática, considerando também a integração do edifício à totalidade do meio ambiente, de forma a torná-lo parte de um conjunto maior. É a arquitetura que quer criar prédios objetivando o aumento da qualidade de vida do ser humano no ambiente construído e no seu entorno, integrando as características da vida e do clima locais, consumindo a menor quantidade de energia compatível com o conforto ambiental, para legar um mundo menos poluído para as próximas gerações.
\end{abstract}

É uma dificuldade projetar edifícios sustentáveis, em virtude da falta de retorno sobre soluções empregadas para atender demandas ambientais. Entretanto, Monteiro, Bittencourt e Yannas (2015) consideram que o projeto do edifício ambiental deve ser entendido como um processo que envolve raciocínio que prioriza questões relacionadas aos impactos que edifícios produzem sobre o meio ambiente e não como um processo diferente, muitas vezes à parte dos procedimentos utilizados na elaboração de projetos convencionais.

Embora seja mais comum encontrar alternativas sustentáveis em projetos de edifícios comerciais, é possível reconhecer na produção arquitetônica residencial multifamiliar exemplares como o edifício Seed, da incorporadora Gamaro (Figura 11), localizado em São Paulo-SP20. Este é um empreendimento pioneiro no segmento residencial a utilizar o conceito de "pocket forest", ou seja, em cada apartamento há um espaço de até $5 \mathrm{~m}^{2}$ destinado ao cultivo de vegetação nativa da mata atlântica brasileira, possibilitando o aumento da umidade e da troca de $\mathrm{CO} 2$ por O2. Além disso, as áreas comuns do edifício serão equipadas 
incluindo vegetação nativa, cultivadas em viveiro próprio e entregues em fase adulta na conclusão das obras do empreendimento.

Outro exemplar é o edifício Llum Batel (Figura 12), localizado em Curitiba-PR ${ }^{21}$. O empreendimento assume a iluminação natural como principal objetivo do projeto e é o primeiro edifício residencial multifamiliar a obter a pré-certificação LEED-CS Ouro 22 adotando cuidados com o consumo de água, energia, além da procedência dos materiais utilizados, bem como o descarte dos mesmos.

Figura 11 - Perspectiva comercial do edifício Seed, em São Paulo-SP, mostrando o conceito do empreendimento.

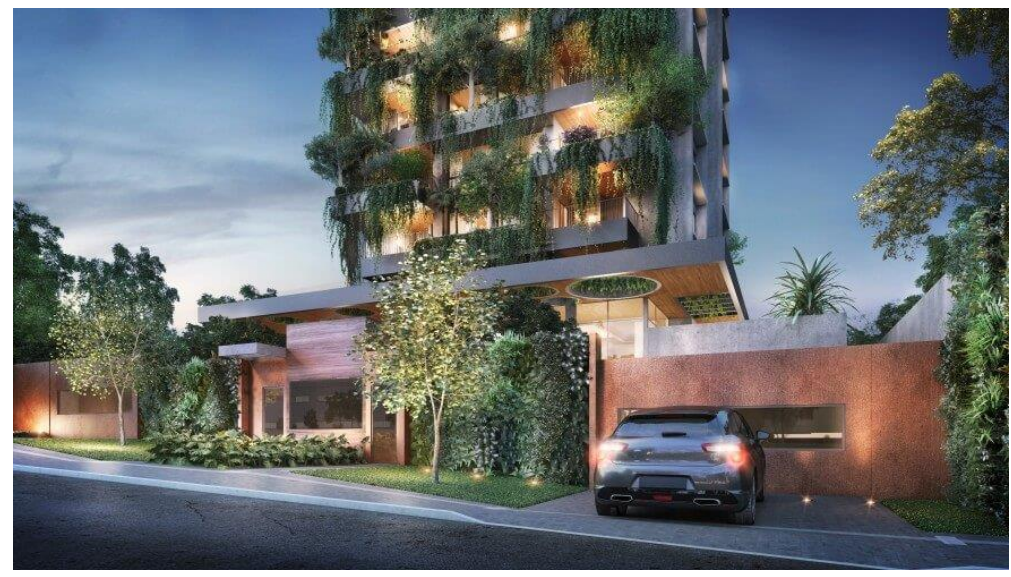

Fonte: Eco4Planet ${ }^{23}$.
Figura 6 - Perspectiva comercial do edifício Llum Batel, em Curitiba-PR.

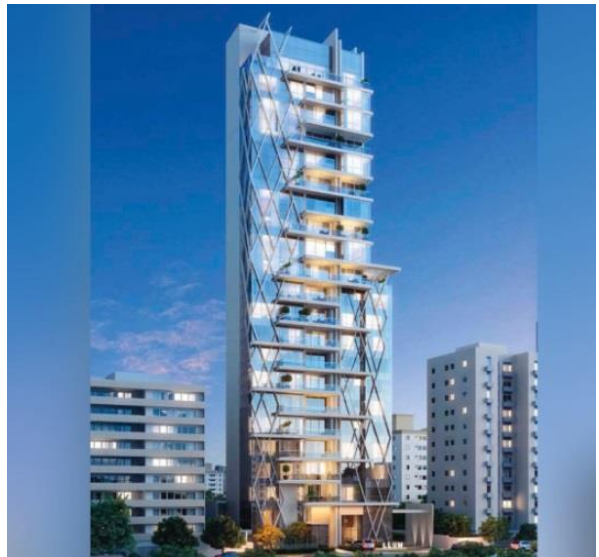

Fonte: Construtora Laguna ${ }^{24}$

\subsection{Integração público x privado}

A integração da edificação (privado) com a rua ou a cidade (público) não é algo novo, mas nos dias atuais, é uma questão que tem se notabilizado, sendo tema de debates, nos quais espaços com uso misto ou também chamados de espaços público-privados, são incentivados, podendo até ser utilizados como contrapartida para que o lote possa ser mais explorado pelo empreendedor. Alguns autores como Ferreira e Marques (2000) discorrem sobre o tema, questionando se essa integração é uma inovação espacial ou ética.

Chacon (2004) afirma que no Rio de Janeiro da década de 20 era muito comum mesclar uso residencial e comercial no mesmo edifício. Villa (2008, p. 33) relata que essa mistura ocorreu de maneira parecida em São Paulo, e foi considerada inovadora e tendência na época: "observa-se que na década de 1910 e 1920 , a grande maioria dos edifícios de apartamentos construídos apresentava algum tipo de comércio no pavimento térreo e, nos demais pavimentos, habitações".

Gavazza e Toledo (2015) analisaram as edificações de uso misto como arquitetura que desempenha um papel importante promovendo benefícios à cidade ao diminuir deslocamentos, criando espaços de convivência e trânsito de pessoas. Os autores chamam atenção para a capacidade que o uso misto tem de proporcionar segurança por meio da criação de espaços de transição entre o público e o privado.

Nesse ponto, Jacobs (2014) se torna uma autora importante ao defender que o movimento, a quantidade de elementos arquitetônicos como portas, recuos, colunas, vitrines, letreiros entre outros, além do contato visual dos pedestres nas calçadas, por ser mais pessoal, cria um ambiente com mais segurança $\mathrm{e}$ qualidade.

O edifício Pop Madalena, localizado em São Paulo, projetado pelo escritório Andrade Morettin Arquitetos Associados, agrega lojas, restaurantes e escritórios, sendo um exemplar de sucesso de edificação de uso misto. O principal acesso é pela cota mais alta do terreno e, de lá, é possível chegar a uma praça na entrada com uma loja voltada para a rua. $O$ projeto ainda permite que a paisagem se integre a áreas de convivência por meio de um mirante (Figuras 13 e 14). 
Figura 7 - Pavimento lazer do edifício Pop Madelena.

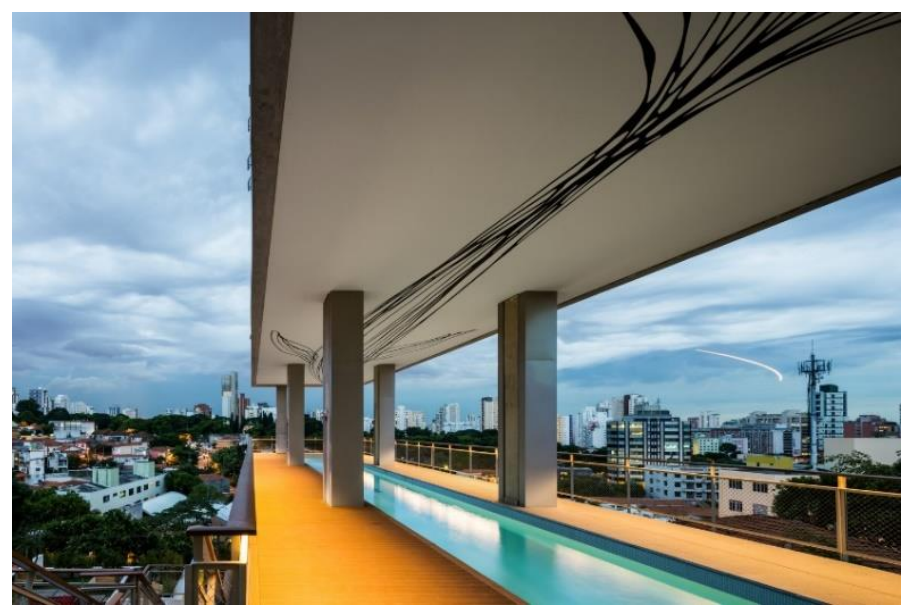

Fonte: Nelson Kon ${ }^{25}$.
Figura 14 - Circulação do edifício Pop Madalena.

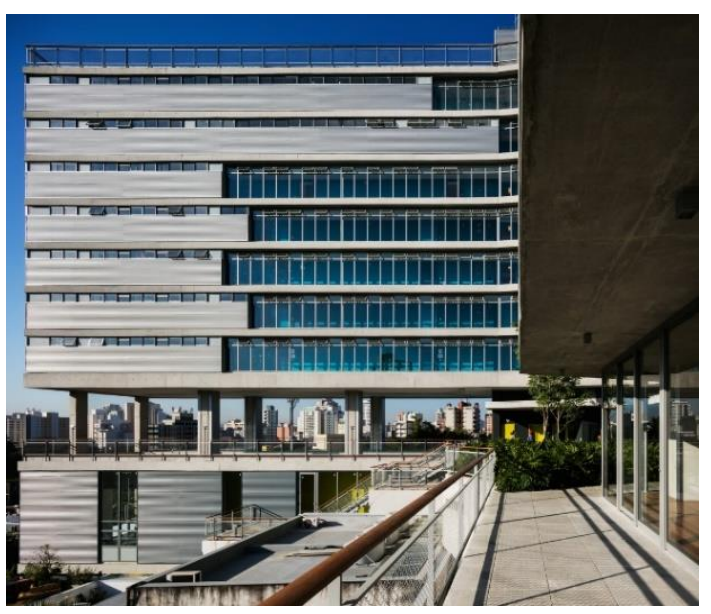

Fonte: Nelson Kon ${ }^{26}$.

Corroborando com a afirmação de que essa preocupação de integrar o edifício e a cidade não é algo recente, pode-se citar o exemplo do edifício Louveira, localizado em Higienópolis, São Paulo e projetado em 1946 por Vilanova Artigas e Carlos Cascaldi. Esse edifício é um importante representante da arquitetura moderna em São Paulo. Mesmo não sendo uma obra recente, o projeto aborda soluções para uma questão contemporânea; sendo um exemplo de arquitetura que permeia de maneira agradável o espaço público ao espaço privado, interligando-os com convivência harmoniosa. A implantação e o os acessos possibilitam a integração visual dos dois espaços, trazendo a praça Vilaboim, localizada em frente, ao interior do lote, sem afetar a privacidade dos moradores do edifício.

Figura 15 - Passeio que dá acesso ao hall de acesso do edifício Louveira.

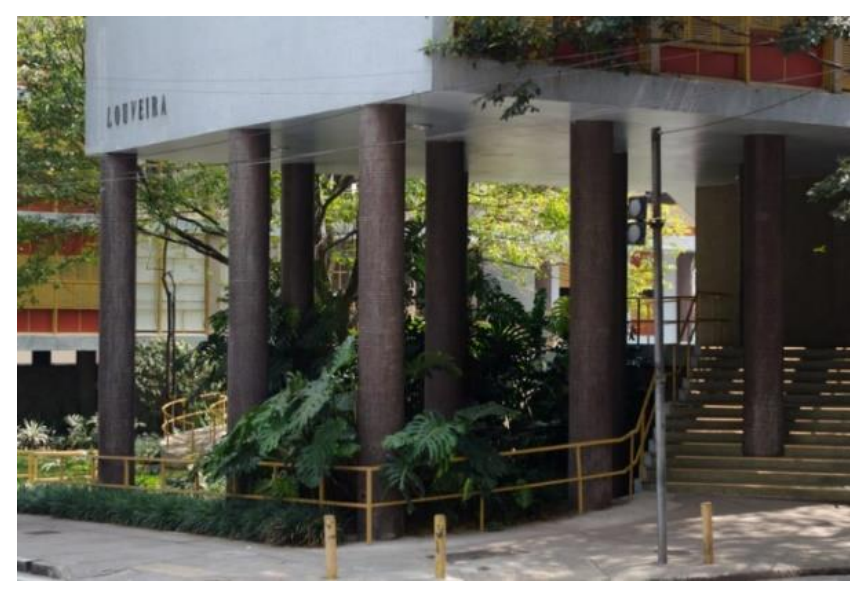

Fonte: Refúgios Urbanos ${ }^{27}$.
Figura 8 - Passeio público em frente ao edifício Louveira.

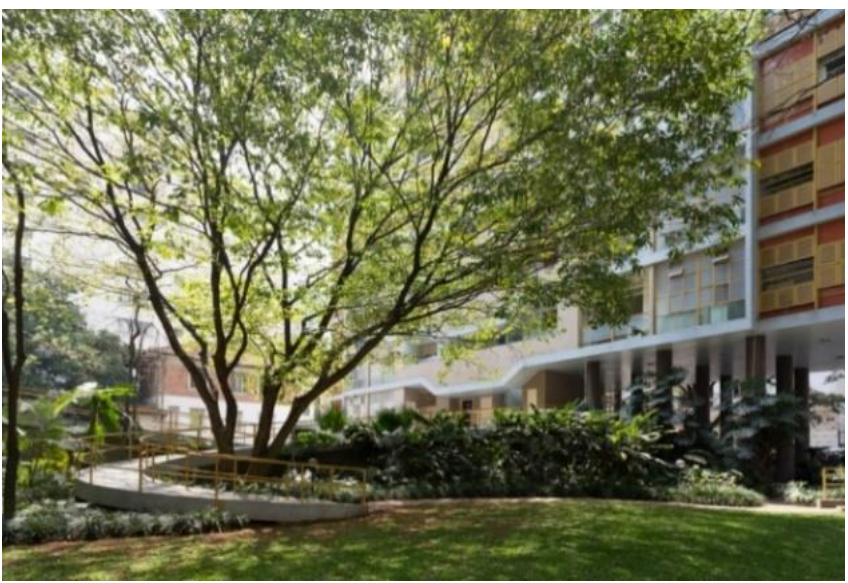

Fonte: Refúgios Urbanos ${ }^{28}$.

Essa integração se dá pelo acesso ao prédio e é muito importante a análise dos acessos. Ching (1998) destacou que há uma relação entre o interior e o exterior que o que delimita é o acesso, a entrada.

Antes de passarmos para o interior de um edifício, nos aproximamos de sua entrada através da via de acesso. Esta constitui a primeira fase do sistema de circulação, na qual somos preparados a ver, experimentar e utilizar os espaços internos de um edifício (CHING, 1998, p. 230). 


\section{CONCLUSÃO}

O termo inovação em arquitetura ainda carece de definições mais precisas e contundentes que possibilitem ir além do significado comumente utilizado, que é o de "novidade, aquilo que é novo", não sendo raro que, em buscas sobre o tema em revistas e premiações de arquitetura, não haja uma explicação sobre o que se considera como inovação, partindo-se do pressuposto de um termo consolidado e autossuficiente para explicar-se.

Uma razão que explica isso é o fato de que a publicidade tem atuado buscando diferenciais em aspectos secundários ao projeto, quando na verdade, existem inovações projetuais, tecnológicas e éticas que as campanhas poderiam explorar. Dessa forma, o foco do marketing nem sempre está nas inovações e sim no entorno, na localização, na grife de morar e no valor de signo atribuído ao empreendimento.

É possível encontrar base para reconhecer elementos de um projeto como critérios de inovação. Primeiramente, a observação de revistas com temática em arquitetura permitiu que a busca pelo termo "inovação" apontasse horizontes por meio dos quais a pesquisa pôde prosseguir e encontrar gatilhos que possibilitaram uma investigação mais específica na produção acadêmica e, dessa forma, fundamentar teoricamente a escolha dos itens como critérios de análise de inovações em edifícios multifamiliares verticais.

Outrossim, percebeu-se que, embora parte da produção arquitetônica seja padronizada e preocupada unicamente em reproduzir tendências de qualidade duvidosa em aspectos projetuais, tecnológicos e éticos, existem muitos edifícios que se destacam por apresentarem alternativas inovadoras ao padrão e dessa forma, conseguem se estabelecer como empreendimentos com qualidades a serem desfrutadas pelos usuários.

Definiram-se, portanto, três tipos de inovações: projetuais, tecnológicas e éticas e seis respectivos critérios de análise: flexibilização de planta, variação tipológica; estrutura e materiais, composição de fachada e volumes; sustentabilidade em projetos de edificações e integração público x privado.

Por fim, concluiu-se que inovação na arquitetura é, de fato, o emprego de novos elementos, desde que sejam de ordem projetual, tecnológica ou ética e que se destaquem na produção padronizada e repetitiva a qual parte do mercado imobiliário se propõe. Por certo, os seis critérios destacados não consistem na totalidade daquilo que pode ser utilizado como critérios de análise de inovações em edifícios multifamiliares verticais, podendo haver outros aspectos a serem estudados em novas pesquisas, mas compõem uma consistente base para que projetos sejam analisados com contundência e especificidade, diferentemente da utilização genérica do termo "inovação" em revistas.

A contribuição deste artigo se deu no âmbito metodológico para novas pesquisas ao possibilitar que inovações sejam analisadas com base em critérios bem definidos, detalhados e criados a partir da observação e estudo da literatura existente sobre o tema. Sem dúvida, à medida que outros pesquisadores se interessem pelo tema, essa lista pode ser ampliada para mais do que os seis critérios apresentados e, mesmo estes listados, podem ser ampliados e revisados de forma a contribuir ainda mais para a pesquisa em arquitetura e urbanismo.

\section{REFERÊNCIAS}

ARGAN, Giulio Carlo. Projeto e destino. 2. ed. São Paulo: Ática, 2001.

AZEVEDO, G. N. Inércia versus inovação: a produção residencial multifamiliar contemporânea em Belo Horizonte e São Paulo. 2014. 359 f. Dissertação (Mestrado) - Curso de Arquitetura e Urbanismo, Escola de Arquitetura da Universidade Federal de Minas Gerais, Universidade Federal de Minas Gerais, Belo Horizonte, 2014.

AZUMA, Fabíola et al. Inovação tecnológica: técnicas e ferramentas aplicadas ao projeto de edificações. Revista Produção Online, Florianópolis, v. 7, n. 3, p.1-17, 5 jul. 2008. Associação Brasileira de Engenharia de Produção ABEPRO. http://dx.doi.org/10.14488/1676-1901.v7i3.70.

BACELLAR, Atlas Augusto; SOUZA, Rubem César R.; MACHADO, Waltair Vieira. Inovação versus competitividade: o caso da alvenaria estrutural na cidade de Manaus. In: Encontro Nacional de Engenharia da Produção, 24., 2012, Florianópolis. Anais.... Florianópolis: ABEPRO, 2012. p. 3608 - 3615

BARROS, Mércia M. S. Bottura de. Metodologia para implantação de tecnologias construtivas racionalizadas na produção de edifícios. Tese (doutorado) Escola Politécnica, Universidade de São Paulo. São Paulo, 1996.

BATISTA, J. O. Inovação e ética: reflexões sobre a pesquisa na pós-graduação em arquitetura e urbanismo. In: SEMINÁRIO NACIONAL DE PESQUISA E PÓS-GRADUAÇÃO EM ARQUITETURA E URBANISMO, 4., 2016, São 
Paulo. Anais do IV Seminário Nacional de Pesquisa e Pós-graduação em Arquitetura e Urbanismo. São Paulo: Universidade Presbiteriana Mackenzie, 2016. p. 1 - 9.

BO BARDI, Lina. "Arquitetura e tecnologia". In: XAVIER, Alberto (org.). Depoimento de uma geração. Arquitetura moderna brasileira. São Paulo: Cosac \& Naify, ed. Revisada e ampliada, 2003, p. 271-3.

CAVALCANTE, Morgana Maria Pitta Duarte. O projeto: diálogos da forma em Maceió: Edifícios verticais: $1980-2012$. 2014. 390 f. Tese (Doutorado em arquitetura e urbanismo) - Curso de Doutorado em Arquitetura e Urbanismo, Programa de Pós-graduação em Arquitetura e Urbanismo, Universidade Presbiteriana Mackenzie, São Paulo, 2014.

CHACON, Sônia. Um estudo tipológico das transformações das edificações multifamiliares no Rio de Janeiro, entre 1930-2000: O caso do bairro de Botafogo. Dissertação (Mestrado em arquitetura e urbanismo) - Programa de PósGraduação em Arquitetura, Universidade Federal do Rio de Janeiro, 2004.

CHING, Francis D. K. Arquitetura. Forma, espaço e ordem. São Paulo: Martins Fontes, 1998.

COLQUHOUN, Alan. Modernidade e tradição clássica. São Paulo: Cosac \& Naify, 2004.

CORBELLA, C.; YANNAS, S. Em Busca de uma Arquitetura Sustentável para os Trópicos - Conforto Ambiental. Revan, Rio de Janeiro. 2003.

COSTA, N. E. P. Marketing imobiliário. Goiânia. AB: 2002.

DUARTE, Alana T. C. G. A influência do uso das tecnologias de informação e comunicação nos espaços domésticos contemporâneos: Uma abordagem em Maceió, Alagoas. 2016. 246 f. Dissertação (Mestrado em arquitetura e urbanismo), Universidade Federal de Alagoas, Maceió, 2016.

EISENMAN, Peter. Diez edificios canónicos 1950-2000. Barcelona: Editorial Gustavo Gili, SL, 2011.

FERREIRA, A. L. de A.; MARQUES, Sônia. Privado e público: inovação espacial ou social? Revista Electrónica de Geografía y Ciencias Sociales, Barcelona, v. 69, n. 20, p.1-11, ago. 2000.

FUCK, Marcos Paulo; VILHA, Anapatrícia Morales. Inovação tecnológica: da definição à ação. Contemporâneos: Revista de artes e humanidades, Campinas, v. 9, n. 1, p.1-21, nov. 2011.

GAVAZZA, Luciana; TOLEDO, Alexandre. Oferta de comércio e serviços em edifícios verticais de uso misto: investigação nas áreas comuns em dois exemplares de Maceió/AL. In: ENCONTRO NACIONAL DE TECNOLOGIA DO AMBIENTE CONSTRUÍDO, 16., 2016, São Paulo. Anais... Porto Alegre: ANTAC, 2016.

GONÇALVES, J. C. S; DUARTE, Denise H. S. Arquitetura sustentável: uma integração entre ambiente, projeto e tecnologia em experiências de pesquisa, prática e ensino. Ambiente Construído, Porto Alegre, v. 4, n. 6, p.51-81, out./dez. 2006.

GRALA DA CUNHA, Eduardo. A abordagem estética no projeto de estruturas de edificações: do ensino à concepção de sistemas estruturais. Arquitextos, São Paulo, ano 11, n. 132.00, Vitruvius, maio 2011 <http://www.vitruvius.com.br/revistas/read/arquitextos/11.132/3870>.

JACOSKI, C. A. Integração e interoperabilidade em projetos de edificações - Uma Implementação com IFC/ XML. Florianópolis, 2003. Tese do Programa de Pós-Graduação em Engenharia de Produção e Sistemas da Universidade Federal de Santa Catarina.

JACOBS, Jane. Morte e vida nas grandes cidades. 3. ed. São Paulo: WMF Martins Fontes, 2014. 296 p. Tradução Carlos S. Mendes Rosa

KOWALTOWSKY, D. C. C. K. Et al. O processo de projeto em arquitetura: da teoria à tecnologia. São Paulo: Oficina de Textos, 2011.

LAWSON, Bryan. Como arquitetos e designer pensam. São Paulo: Oficina de Textos, 2011. 296 p.

MAFHUZ, E. da C. Nada provém do nada. Revista Projeto, São Paulo: Arco, n. 69, p. 89-95, nov. 1984.

MACIEL, Carlos Alberto. Técnica moderna: entre o monumento e a construção cotidiana. In: Revista Mínimo Denominador Comum - Revista de Arquitetura e Urbanismo, Ano 1 N. 3, março de 2006. pp. 22- 24.

MONTANER, Josep Maria. A modernidade superada: arquitetura, arte e pensamento do século XX. Barcelona: Gustavo Gili, 2001.

MONTEIRO, L.; BITTENCOURT, L. S.; YANNAS, S. Cap. 1: Arquitetura da adaptação.1.2 Considerações preliminares sobre o projeto do edifício ambiental. In: Joana Carla Soares Gonçalves; Klaus Bode. (Org.). Edifício Ambiental. 1ed.São Paulo: Oficina de textos, 2015, v., p. 36-46.

NIEMEYER, Oscar. "A forma na arquitetura". In: XAVIER, Alberto (org.) Depoimento de uma geração. Arquitetura moderna brasileira. São Paulo: Cosac \& Naify, Edição revisada e ampliada, 2003, p. 141-5.

OLIVEIRA, Talita Y. M. de. Estudo sobre o uso de materiais alternativos que otimizam a sustentabilidade em edificações. 2015. 99 f. TCC (Graduação) - Curso de Engenharia Civil, Escola Politécnica, Universidade Federal do Rio de Janeiro, Rio de Janeiro, 2015. 
PISANI, M. A. J; GIL, Erica Lemos. Arquitetura é construção. Arq.Urb, São Paulo, v. 1, n. 7, p.8-16, jan. 2012.

REPORT, Brundtland. Nosso Futuro Comum. 2. ed. Rio de Janeiro: Fundação Getúlio Vargas, 1991.

SEGNINI, Francisco. "Prefácio". In: VARGAS, Heliana Comin; ARAUJO, Cristina Pereira de (Org.). Arquitetura e mercado imobiliário. Barueri: Manole, 2014. p. XV-XVIII.

TRAMONTANO, M. SQCB: apartamentos e vida privada na cidade de São Paulo. Tese de Livre Docência. São Carlos: EESC-USP, 2004.

VARGAS, H. C. "O arquiteto e seus clientes." In: VARGAS, Heliana Comin; ARAUJO, Cristina Pereira de (Org.). Arquitetura e mercado imobiliário. Barueri: Manole, 2014. Cap. 1. p. 1-14.

VARGAS, H. C. Publicidade imobiliário: o que se está vendendo? In: VARGAS, H. C.; ARAÚJO, Cristina Pereira de (Org.). Arquitetura e mercado imobiliário. Barueri: Manole, 2014. Cap. 4. p. 53-71.

VARGAS, H. C.; ARAÚJO, Cristina Pereira de (Org.). Arquitetura e mercado imobiliário. Barueri: Manole, 2014.

VILHA, Anapatrícia Morales. Gestão da inovação na indústria brasileira de higiene pessoal, perfumaria e cosméticos: uma análise sob a perspectiva do desenvolvimento sustentável. Tese de Doutorado no Departamento de Política Científica e Tecnológica, Instituto de Geociências - UNICAMP, Campinas, 2009.

VILLA, Simone Barbosa; ORNSTEIN, Sheila Walbe. Projetar Apartamentos com vistas à qualidade arquitetônica a partir dos resultados da avaliação pós-ocupação (APO). Gestão \& Tecnologia de Projetos, [s.l.], v. 4, n. 2, p.35-60, 11 nov. 2010. Universidade de São Paulo Sistema Integrado de Bibliotecas - SIBiUSP.

XAVIER, Regina. Indícios de flexibilidade no projeto de edifícios multifamiliares em Maceió-AL (1980-1985): surgimento e apropriação do ambiente reversível pelos usuários de apartamentos. 2016. $184 \mathrm{f}$. Dissertação de (Mestrado em Arquitetura e Urbanismo), Faculdade de Arquitetura e Urbanismo, Universidade Federal de Alagoas, Maceió, 2016.

\section{NOTAS}

${ }^{1}$ Associação das Empresas do Mercado Imobiliário de Alagoas, a ADEMI-AL tem por objetivo firmar parcerias com empresas do ramo da construção civil e atribuir qualidade aos produtos do mercado imobiliário promovendo discussões, eventos, capacitações, entre outros, e premia por meio do Prêmio Master ADEMI-AL empresas e profissionais cujos empreendimentos se destaquem no cenário alagoano imobiliário.

2 Projeto arquitetônico do escritório RoccoVidal Perkins+Will. Construção MaxHaus. Rua Dr. Jesuíno Maciel, 1.682 - Campo Belo.

${ }^{3}$ Disponível em: https://www.archdaily.com.br/br/758483/edificio-campo-belo-roccovidal-p-plus-w/547e93b4e58eceb3be000060, acesso em 20/09/2018

${ }^{4}$ Disponível em: https://www.archdaily.com.br/br/758483/edificio-campo-belo-roccovidal-p-plus-w/547e943fe58eceb3be000067, acesso em 20/09/2018.

${ }^{5}$ R. Quatá, 76 - Vila Olimpia, São Paulo - SP.

${ }^{6}$ Criado pelo canadense Graham Hill em Nova lorque, Life Edited é um conceito de moradia que aposta em aplicar conceitos e tecnologias inteligentes, possibilitando que o usuário se adeque à necessidade dele primando pela funcionalidade e praticidade em um apartamento a um custo menor:

${ }^{7}$ Disponível em: https://vitacon.com.br/empreendimentos/vn-quata/, acesso em 20/09/2018.

${ }^{8}$ Disponível em: https://vitacon.com.br/empreendimentos/vn-quata/, acesso em 20/09/2018.

${ }^{9}$ No artigo de Gavazza e Toledo (2016) a tipologia se limita metodologicamente à quantidade de dormitórios que existem em determinada unidade habitacional, no entanto, o conceito de variação tipológica se aplica ao presente artigo em virtude de o foco ser como o apartamento varia em decorrência dos hábitos de morar em constante mudança.

${ }^{10}$ Rua Fidalga 727 - Pinheiros, São Paulo - SP

${ }^{11}$ Disponível em: https://www.archdaily.com.br/br/01-13719/fidalga-727-triptyque/5745a56fe58ece6750000001-fidalga-727-triptyquerender, acesso em 20/09/2018

${ }^{12}$ Disponível em: https://www.archdaily.com.br/br/01-13719/fidalga-727-triptyque/5745a5c2e58ece6750000003-fidalga-727-triptyqueesquema-plantas, acesso em 20/09/2018.

${ }^{13} \mathrm{O}$ autor cita duas obras do arquiteto Santigo Calatrava: o Centro de Artes Visuais, Valência-ESP; e a estação de metrô da EXPO 1997 em Lisboa-POR.

${ }^{14}$ Disponível em: http://dhiimoveis.com.br/maxhaus-porto-alegre/, acesso em 04/02/2018.

${ }^{15}$ Disponível em: http://picbear.online/zampieriimoveis, acesso em 04/02/2018.

${ }^{16}$ R. Padre Luiz Américo Galvão, 12 - Cruz das Almas, Maceió - AL

${ }^{17}$ R. Fidalga, 727 - Pinheiros, São Paulo - SP

${ }^{18}$ Disponível em: http://ritzincorporacoes.com.br/ritz-residence/, acesso em 21/09/2018.

${ }^{19}$ Disponível em: https://www.archdaily.com.br/br/01-13719/fidalga-727-triptyque/500704b128ba0d4148000a84-fidalga-727-triptyquephoto, acesso em 21/09/2018.

${ }^{20}$ Rua Casa do Ator, 200 - Vila Olímpia, São Paulo - SP, 04546-001

${ }^{21}$ Av. Visc. de Guarapuava, 5345 - Batel, Curitiba - PR, 80240-010 
22 O selo LEED (Leadership in Energy and Environmental Design), na categoria "CS" se aplica a projetos na envoltória e na parte central do edifício. Já a qualificação "Gold" é a segunda maior, atrás apenas da certificação "Platinum".

${ }^{23}$ Disponível em: http://eco4planet.com/blog/seed-terraco-pocket-forest-sao-paulo-vila-olimpia/, acesso em 28/11/2018.

${ }^{24}$ Disponível em: https://www.construtoralaguna.com.br/imoveis-residenciais/lum-batel\#/conceito, acesso em 28/11/2018.

${ }^{25}$ Disponível em: https://www.archdaily.com.br/br/867005/edificio-pop-madalena-andrade-morettin-arquitetosassociados/58c4aaf0e58ece278c00005a-edificio-pop-madalena-andrade-morettin-arquitetos-associados-foto, acesso em 21/09/2018.

${ }^{26}$ Disponível em: https://www.archdaily.com.br/br/867005/edificio-pop-madalena-andrade-morettin-arquitetos-

associados/58c4b038e58eceee16000028-edificio-pop-madalena-andrade-morettin-arquitetos-associados-foto, acesso em 21/09/2018.

${ }^{27}$ Disponível em: http://refugiosurbanos.com.br/casas-predios/louveira/, acesso em 28/03/2018.

${ }^{28}$ Disponível em: http://refugiosurbanos.com.br/casas-predios/louveira/, acesso em 28/03/2018

NOTA DO EDITOR (*) O conteúdo do artigo e as imagens nele publicadas são de responsabilidade do(s) autor(es). 